This is the peer reviewed version of the following article:

Barwe, S. et al. Polybenzoxazine-derived N-doped carbon as matrix for powder-based electrocatalysts in ChemSusChem (Ed. Wiley), vol. 10, issue 12 (June 2017), p. 2653-2659.

Which has been published in final form at DOI 10.1002/cssc.201700593.

This article may be used for non-commercial purposes in accordance with Wiley terms and conditions for use of self-archived versions.

This version in DDD has been published under a "All rights reserved" licesne. 


\title{
Polybenzoxazine-Derived N-doped Carbon as Matrix for Powder-Based Electrocatalysts
}

\author{
Stefan Barwe ${ }^{[a]}$ Corina Andronescu, ${ }^{[a, b]}$ Justus Masa, ${ }^{[a]}$ Edgar Ventosa, ${ }^{[a, ~ e] ~ S t e f a n ~ K l i n k, ~}{ }^{[a]}$ \\ Aziz Genç, ${ }^{[c]}$ Jordi Arbiol, ${ }^{[c, d]}$ and Wolfgang Schuhmann ${ }^{*[a]}$
}

\begin{abstract}
In addition to catalytic activity, intrinsic stability, tight immobilization on a suitable electrode surface, and sufficient electronic conductivity are fundamental prerequisites for the long-term operation of particle- and especially powder-based electrocatalysts. We present a novel approach to concurrently address these challenges by using the unique properties of polxbenzoxazine $(\mathrm{pBO})$ polymers, namely near-zero shrinkage and high residual-char yield even after pyrolysis at high temperatures.
\end{abstract}

Pyrolysis of a nanocubic prussian blue analogue precursor $\left(\mathrm{K}_{m} \mathrm{Mn}_{x}\left[\mathrm{Co}(\mathrm{CN})_{6}\right]_{y} \times n \mathrm{H}_{2} \mathrm{O}\right)$ aok? nol $\mathrm{A}$ and aniline-based $\mathrm{pBO}$ led to the formation of an $\mathrm{N}$ doped carbon matrix modified with $\mathrm{Mn}_{x} \mathrm{Co}_{y} \mathrm{O}_{z}$ nanocubes. The obtained electrocatalyst exhibits high efficiency toward the oxygen evolution reaction (OER) and more importantly a stable performance for at least $65 \mathrm{~h}$.

\section{Introduction}

Electrocatalytic splitting of water into hydrogen and oxygen is limited by high overpotentials of the oxygen evolution reaction (OER). ${ }^{[1]}$ Low-cost, non-precious, earth-abundant metals and their oxides and oxyhydroxides are subject of efforts in catalyst research aiming to reduce the overpotential needed to drive the kinetically sluggish OER.$^{[2]}$ However, the obtained materials are typically catalyst powders, which have to be brought in contact with the electrode surface maintaining fast electrontransfer pathways especially among the powder particles as well as stable fixation under vigorous gas evolution at high current densities. The lack of strategies for the fixation of powder catalysts leads to suboptimal catalyst performance es-

[a] S. Barwe, Dr. C. Andronescu, Dr. J. Masa, Dr. E. Ventosa, Dr. S. Klink, Prof. Dr. W. Schuhmann

Analytical Chemistry, Center for Electrochemical Sciences (CES) Ruhr-Universität Bochum

44780 Bochum (Germany)

E-mail:wolfgang.schuhmann@rub.de

[b] Dr. C. Andronescu

Advanced Polymer Materials Group

University Politehnica of Bucharest

1-7 Gh. Polizu street, 011061 Bucharest (Romania)

[c] Dr. A. Genç, Prof. Dr. J. Arbiol

Institut Català de Nanociència i Nanotecnologia; ICN2

Campus de la UAB

08193 Bellaterra, CAT (Spain)

[d] Prof. Dr. J. Arbiol

Institució Catalana de Recerca i Estudis Avançats

ICREA

08010 Barcelona, CAT, (Spain)

[e] Dr. E. Ventosa

Present address:

IMDEA Energy Institute

Avda. Ramón de la Sagra 3, 28935 Móstoles, Madrid (Spain)

(iD Supporting Information and ORCID identification number(s) for the author(s) of this article can be found under https://doi.org/10.1002/ cssc.201700593. pecially with respect to stability during operation at high current densities. Organic polymers are typically used as binder materials, although they might be insulating if used in too high concentrations, thus blocking catalytically active sites and decreasing the intrinsic activity of the catalyst. ${ }^{[3]}$ Even in alkaline electrolytes, in which abundant transition metal-based catalysts can be used $\square$ ok? $\square$, Nafion is often used as binder material, which can be considered unsuitable under these conditions due to covering surface active sites and its intrinsic insulating properties. Evidently, it is important to enhance the intrinsic conductivity of electrocatalysts, especially when poorly conducting materials are used or poorly conducting binder materials are added. The addition of carbon nanomaterials such as carbon black, carbon nanotubes, or graphene oxide/reduced graphene oxide is commonly used to enhance the conductivity of related slurry electrodes. ${ }^{[4]}$ However, mixtures of carbon additives with powder-based electrocatalysts do not overcome limitations imposed by the poor adhesion on the electrode surface and typically an unsuitable binder material such as Nafion is used to glue the catalyst/carbon composite powder to the electrode surface.

We present the first application of polybenzoxazines (pBO), a class of high-performance thermosets, as new binder matrices in electrocatalysis to concurrently address the aforementioned issues in powder-catalyst fixation. pBOs consist of highly crosslinked networks of benzoxazine (BO) monomers or oligomers. ${ }^{[5]}$ They arise from Mannich-type reactions of primary amines, aldehydes, and phenol derivatives. ${ }^{[5]}$ Especially, two unique features of this specific polymer class make pBOs highly suitable as precursors for electrocatalyst matrices: i) near-zero shrinkage with respect to the deposited monomer film during polymerization, which allows for maintaining a homogeneous electrode coating after polymerization whereas other types of polymers shrink upon solvent evaporation 
hence weakening the catalyst film adhesion on electrode surfaces. ii) Highly crosslinked pBO networks are well known as flame-retardant materials providing high residual char yields after pyrolysis, an important prerequisite for the formation of a stable carbon-based binder matrix. ${ }^{[6]}$ Thus, subsequent polymerization and pyrolysis transform the insulating organic $\mathrm{pBO}$ matrix into a conducting carbon matrix ${ }^{[7]}$ with incorporated electrically interconnected catalyst powder particles exhibiting high physical stability.

Our strategy is to embed the prussian blue analogue (PBA) potassium manganese hexacyanocobaltate $\left(\mathrm{K}_{m} \mathrm{Mn}_{x}\left[\mathrm{Co}(\mathrm{CN})_{6}\right]_{y} \times\right.$ $n \mathrm{H}_{2} \mathrm{O}$ ) as a model catalyst precursor into a benzoxazine-based precursor matrix. A sequence of polymerization and pyrolysis converts the composite into $\mathrm{Mn}$ - and Co-containing nanocubes embedded into a pBO-derived carbon matrix forming a highly stable OER active film on the electrode.

\section{Results and Discussion}

\section{Three-step electrode preparation}

Catalyst particles embedded in a porous $\mathrm{N}$-doped carbon matrix were prepared according to the three-step procedure shown in Scheme 1 and described in detail in the Experimental

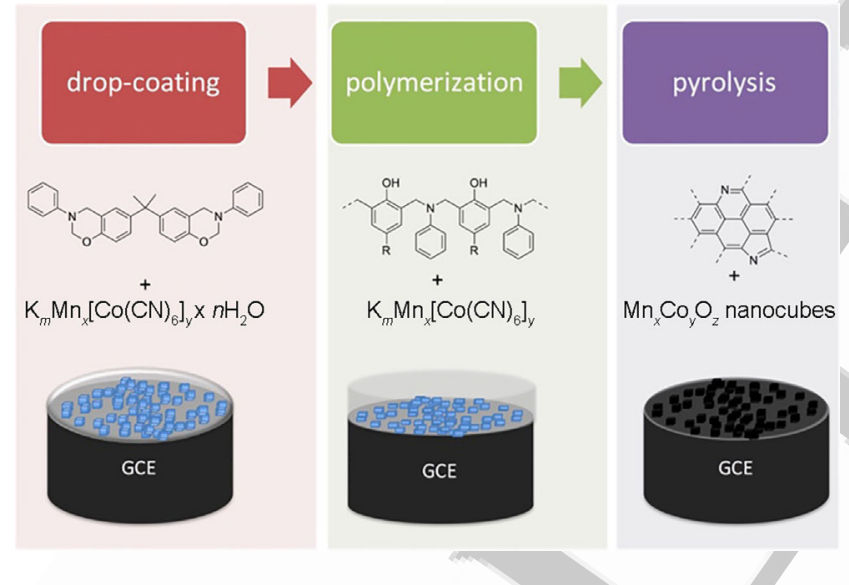

Scheme 1. Electrode preparation procedure and transformation of the precursor materials into the final catalyst.

Section. Thermally induced polymerization of a mixed film of a bisphenol A and aniline-based BO monomer and $\mathrm{K}_{m} \mathrm{Mn}_{x}\left[\mathrm{Co}(\mathrm{CN})_{6}\right]_{y}$ drop-coated on a glassy carbon electrode surface led to a polymer layer with incorporated PBA particles. Subsequent pyrolysis transformed the deposited pBO/PBA film into a conducting $\mathrm{N}$-doped carbon matrix incorporating mildly oxidized $\mathrm{Mn}$ and $\mathrm{Co}$ nanocubes (carbon- $\mathrm{Mn}_{x} \mathrm{Co}_{y} \mathrm{O}_{z}$; Scheme 1).

The unique near-zero shrinkage property of $\mathrm{pBOs}$ led to a homogenously distributed carbon matrix over the electrode surface even after pyrolysis (Figure S1 in the Supporting Information). The modified electrode was entirely covered with $\mathrm{Mn}_{x} \mathrm{Co}_{y} \mathrm{O}_{z}$ nanocubes and with relatively larger particles representing agglomerates of the nanocubes (Figure S1). Polymerization and pyrolysis were performed under Ar flow to prevent complete degradation of $\mathrm{pBO}$. However, although the thermal treatment was performed under inert gas atmosphere, Mn was oxidized by traces of oxygen at higher temperatures. This was also observed after pyrolysis of the pure PBA precursor. The Mn core-level XPS spectrum shows a $M n 2 p_{3 / 2}$ peak with a binding energy of $641.48 \mathrm{eV}$, representing an oxidized manganese $\left(\mathrm{Mn}^{2+} / \mathrm{Mn}^{3+}\right)$ species (Figure S2). Thermogravimetric analysis (TGA) of the two precursors (PBA and $\mathrm{pBO}$ ) was employed to gain further insight into the influence of the temperature during the polymerization and pyrolysis processes on the decomposition behavior (Figure 1). In a first step, the tempera-

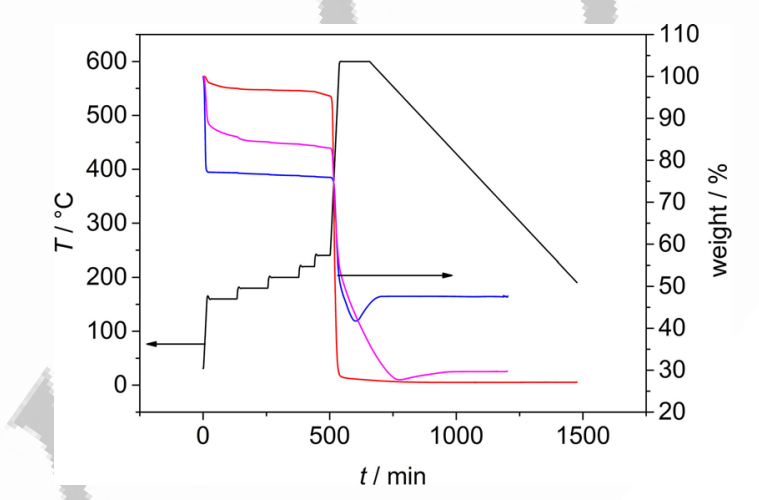

Figure 1. TGA of Araldite (red line), $\mathrm{K}_{m} \mathrm{Mn}_{x}\left[\mathrm{Co}(\mathrm{CN})_{6}\right]_{y} \times n \mathrm{H}_{2} \mathrm{O}$ (blue line), and a 1:1 mixture of Araldite and $\mathrm{K}_{m} \mathrm{Mn}_{x}\left[\mathrm{Co}(\mathrm{CN})_{6}\right]_{y} \times n \mathrm{H}_{2} \mathrm{O}$ (purple line).

ture was increased stepwise from room temperature to $240^{\circ} \mathrm{C}$ inducing $\mathrm{BO}$ polymerization, resulting only in a minor weight loss of the pure $\mathrm{pBO}$ owing to evaporation of residual solvent. A further increase of the temperature to $600^{\circ} \mathrm{C}$ during pyrolysis led to an additional drastic weight loss of $68 \%$ caused by loss of volatile fragments from the degradation of the polymer chain (i.e., aniline). The pBO gave a residual char yield of $27 \%$ after the complete thermal treatment. The behavior of the pure PBA was dominated by three major weight changes during the thermal treatment. First, a weight loss of $23 \%$ occurred during the first heating step, caused by evaporation of crystal water of the PBA. A second weight loss of $35 \%$, after reaching $350{ }^{\circ} \mathrm{C}$, was owed to the release of cyanide groups of the PBA as cyanogen. The observed behavior conforms well to the pyrolysis of PBAs as previously reported. ${ }^{[8]} \mathrm{A}$ weight increase of $5 \%$ further indicates the formation of metal oxides as supported by the previously mentioned XPS results. A mixture of the $\mathrm{pBO}$ and PBA with a ratio of 1:1 (wt \%) followed a similar behavior as the two starting materials, but the decomposition at high temperature was hampered compared to the pure PBA leading to a residual char yield of $30 \%$.

\section{Influence of the PBA-to-pBO ratio}

The influence of the $\mathrm{pBO}$ content on the OER activity of the PBA-derived electrocatalyst was investigated by means of hydrodynamic cyclic voltammetry using electrodes prepared with $0,2,10,17,28$, or $50 \mathrm{wt} \% \mathrm{pBO}$ with respect to the overall solid content in the drop-coated ink (Figure $2 a, b$ ). The voltam- 

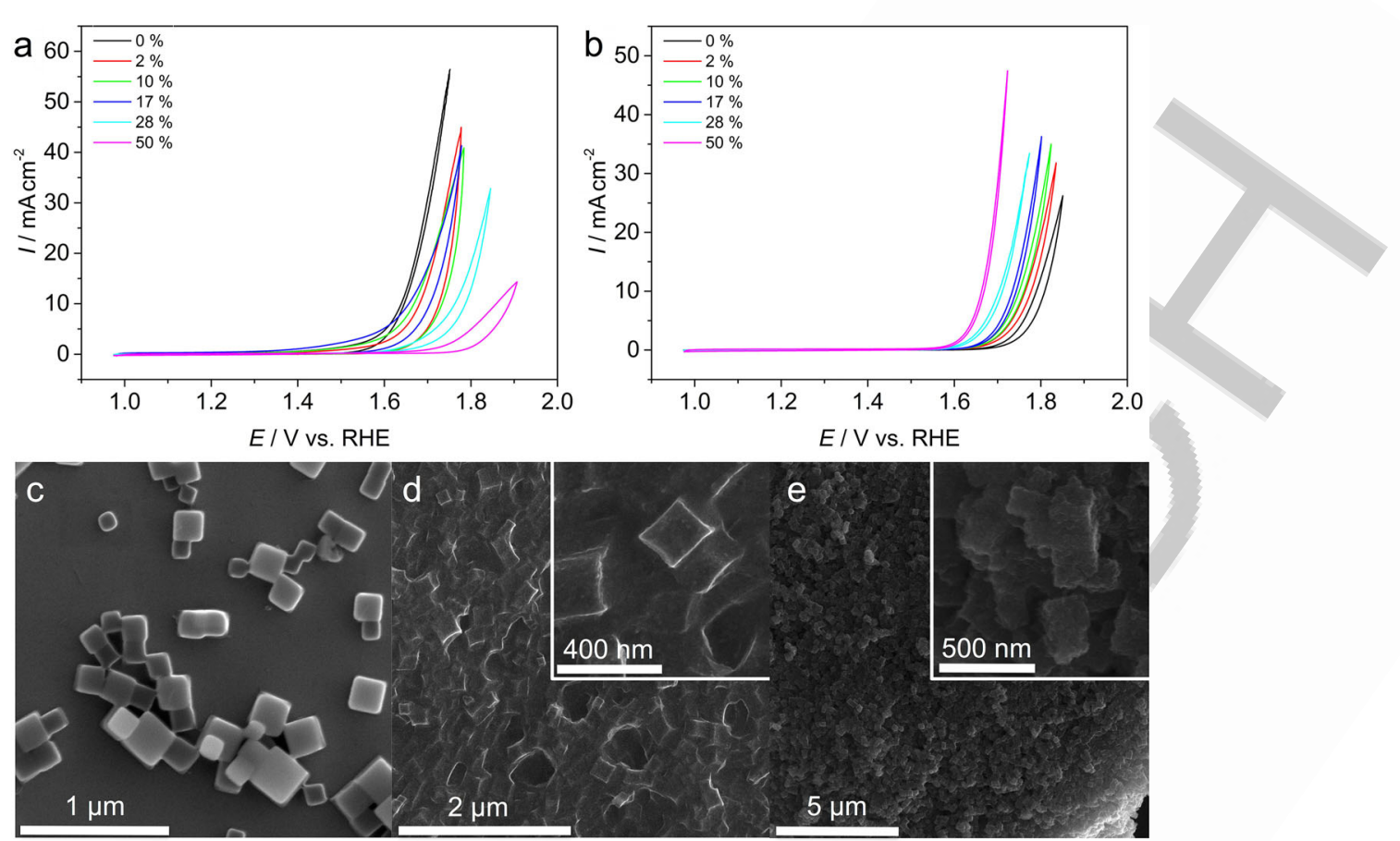

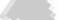

Figure 2. RDE cyclic voltammograms (scan rate $5 \mathrm{mVs}^{-1}, 0.1 \mathrm{M} \mathrm{KOH}, \mathrm{O}_{2}$-saturated, $1600 \mathrm{rpm}$ ) of GCEs modified with different amounts pBO in the drop-coating solutions $(0,2,10,17,28$, and $50 \mathrm{wt} \%$ of solid content in solution) before (a) and after potential cycling (b). SEM images of as-prepared $\mathrm{K}_{m} \mathrm{Mn}_{x}\left[\mathrm{Co}(\mathrm{CN})_{6}\right]_{y} \times n \mathrm{H}_{2} \mathrm{O}$ (c), carbon- $\mathrm{Mn}_{x} \mathrm{Co}_{y} \mathrm{O}_{z}$ before (d) and after (e) potentiodynamic activation.

mograms of the as-prepared samples indicate a clear decline of the catalytic activity with increasing $\mathrm{pBO}$ :PBA ratio (Figure $2 \mathrm{a}$ ). These observations suggest that during the pyrolysis step a catalytically inactive carbon matrix is formed from $\mathrm{pBO}$ masking the catalytically active sites on the embedded metal oxide particles. However, consecutive potential cycling (50 cycles, scan rate $50 \mathrm{mV} \mathrm{s}^{-1}$ ) substantially activates the catalytic activity of the modified electrodes prepared with 28 and $50 \mathrm{wt} \% \mathrm{pBO}$ whereas all other electrodes lost activity because of insufficient catalyst fixation on the electrode surface caused by the low $\mathbf{\square}$ ok? amount of pBO during film formation (Figure $2 \mathrm{~b}$ ). Samples before and after electrochemical cycling are referred to as "as-prepared" and "pretreated", respectively. The pretreatment process apparently eliminates amorphous carbon layers, thus exposing more highly active sites to the electrolyte, concomitantly reducing the required overpotential for OER. The carbon removal can be considered as self-limiting. After activation, the catalysts with a pBO content of $50 \mathrm{wt} \%$ showed the highest activity. The activation effect explains the different surface morphologies seen in the SEM images of the as-prepared and pretreated electrodes with $50 \mathrm{wt} \%$ pBO (Figure $2 \mathrm{~d}$ and $2 \mathrm{e}$ ).

The SEM image of the as-prepared electrode shows the $\mathrm{Mn}_{x} \mathrm{Co}_{y} \mathrm{O}_{z}$ nanocubes covered with an additional layer, whereas the image of the pretreated electrode reveals uncovered and porous $\mathrm{Mn}_{x} \mathrm{Co}_{y} \mathrm{O}_{z}$ nanocubes. Transmission electron microscopy (TEM) of the pretreated samples revealed the presence of a sufficient amount of graphitic carbon providing on the one hand high conductivity and on the other hand a matrix of improved stability (Figures S3-S5). $\mathrm{Mn}_{x} \mathrm{Co}_{y} \mathrm{O}_{z}$ nanocubes obtained without any addition of $\mathrm{pBO}$ showed an initial high activity during the first voltammogram, however, the catalyst detached easily from the electrode surface leading to drastic activity loss (Figure $2 \mathrm{a}, \mathrm{b})$. Stabilization of the $\mathrm{Mn}_{x} \mathrm{Co}_{y} \mathrm{O}_{z}$ nanocubes using Nafion as a binder leads to a substantially less active and less stable film (Figure S6) compared to the activated sample containing a PBA/pBO ratio of 1:1, thus clearly confirming the benefit of using $\mathrm{pBO}$-derived carbon networks for incorporating catalyst particles compared to the most commonly used binder. SEM revealed the preservation of the cubic structure of the precursor material during the heat-treatment processes (Figure 2c-e).

\section{Catalyst characterization}

A sample containing $50 \mathrm{wt} \% \mathrm{pBO}$ was investigated by means of SEM, X-ray diffraction (XRD), X-ray photoelectron spectroscopy (XPS), and TEM-related techniques such as high-resolution TEM (HRTEM), scanning TEM (STEM) in the high-angle annular dark field mode (HAADF), and STEM-electron energy loss spectroscopy (EELS). The edge length of the cubic catalyst particles varied between 120 and $270 \mathrm{~nm}$ and was independent of the preparation step (Figure S7). Energy dispersive X-ray spectroscopy (EDX) and XPS revealed the presence of the expected components $\mathrm{Mn}, \mathrm{Co}, \mathrm{O}$, and $\mathrm{C}$ (Figures S8 and S9) in the catalyst layer. HRTEM micrographs revealed a mixed amorphous/ graphitic carbon layer covering the whole structure, confirming the results from the SEM images (Figure $2 \mathrm{c}$ ). The existence of mixed amorphous/graphitic carbon was further confirmed by Raman spectroscopy (Figure S15), XPS (Figure 4), and XRD (Figure 5). HAADF STEM micrographs show the presence of small nanoparticles and the presence of flake-like regions em- 
bedded in a graphitic carbon matrix (Figures $3 \mathrm{a}, \mathrm{b}, \mathrm{S} 12-\mathrm{S} 14)$. Moreover, Co is shown to partly remain as metallic Co (Figures $3 \mathrm{e}, \mathrm{S5}, \mathrm{S10}$, and S11), whereas $\mathrm{Mn}$ is only present in its oxide forms and could not be observed in its metallic state, supporting the earlier statement of its tendency to be oxidized. Furthermore, a Mn-, Co-, and C-containing phase seems to exist (Figure $3 \mathrm{e}$ ).

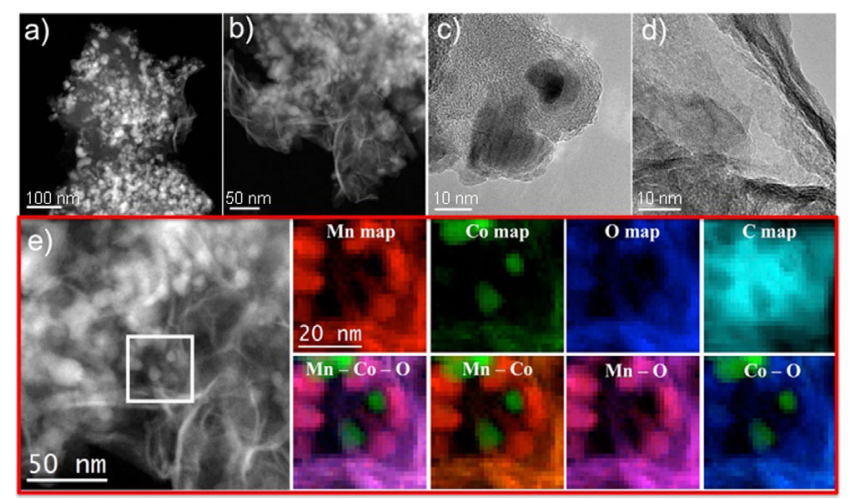

Figure 3. TEM analysis of as-prepared carbon- $\mathrm{Mn}_{x} \mathrm{Co}_{y} \mathrm{O}_{z}$. HAADF STEM $(\mathrm{a}, \mathrm{b})$ and HRTEM (c,d) micrographs of the carbon- $\mathrm{Mn}_{x} \mathrm{Co}_{y} \mathrm{O}_{z}$ composite showing several nanoparticles with a flake-like structure and the $C$ matrix. EELS mapping was obtained from the white squared area. Individual EELS composition maps of $\mathrm{Mn}$ (red), Co (green), $\mathrm{O}$ (blue), and $\mathrm{C}$ (turquoise) along with the composites maps of $\mathrm{Mn}-\mathrm{Co}-\mathrm{O}, \mathrm{Mn}-\mathrm{Co}, \mathrm{Mn}-\mathrm{O}$, and $\mathrm{Co}-\mathrm{O}$ (e).

Additional STEM EELS maps also show a partial segregation of $\mathrm{Mn}$ and $\mathrm{Co}, \mathrm{Mn}$-rich oxides and $\mathrm{Co} / \mathrm{MnCoO}$ core-shell particles (Figures S5, S10, and S11). Furthermore, XRD and XPS revealed the existence of metal carbide phases (Figures 5 and 4), which are in good agreement with the literature about pyrolysis of PBA in inert atmosphere at $600^{\circ} \mathrm{C} .^{[8]}$ The $\mathrm{C} 1 \mathrm{~s}$ spectrum (Figure 4C) was deconvoluted into five peaks with binding energies at 283.52, 284.22, 285.36, 288, and $291.57 \mathrm{eV}$ corresponding to metallic carbides, $\mathrm{sp}^{2} \mathrm{C}-\mathrm{C}, \mathrm{C}-\mathrm{O}-\mathrm{C} / \mathrm{C}-\mathrm{N}, \mathrm{O}=\mathrm{C}-\mathrm{O}$, and a shake-up feature, respectively. ${ }^{[9]}$ The peak at $283.52 \mathrm{eV}$ can be safely assigned to carbides of $\mathrm{Co}$ and $\mathrm{Mn}$ owing to its good conformance to the $\mathrm{C} 1 \mathrm{~s}$ energies of other transition metal carbides, and is therefore in accordance with the $\mathrm{MnCoC}$ phase in Figure $3 e^{[10]}$ Deconvolution of the N 1s spectrum revealed the presence of pyridinic $\mathrm{N}(399.09 \mathrm{eV})$ and pyrrolic $\mathrm{N}$ $(401.06 \mathrm{eV})$ groups (Figure $4 \mathrm{e}$ ), and hence the formation of $\mathrm{N}$ doped carbon as described previously by Zhang et al. for the pyrolysis of the used $\mathrm{pBO} .^{[11]}$ The presence of $\mathrm{Co}^{2+}$ is difficult to conclude from the binding energies of the $\operatorname{Co} 2 p_{1 / 2}$ and Co $2 p_{3 / 2}$ peaks (Figure $4 b$ ). ${ }^{[12]}$ However, both Co $2 p$ peaks have characteristic satellite features at higher binding energies, supporting the presence of $\mathrm{Co}^{2+}$ ions. ${ }^{[13]}$ The absence of satellite features in the $\mathrm{Mn} 2 \mathrm{p}$ (Figure $4 \mathrm{a}$ ) spectrum and the peak splitting of $5.5 \mathrm{eV}$ in the binding energy of the $\mathrm{Mn} 3 \mathrm{~s}$ spectrum (Figure $4 \mathrm{f}$ ) confirms the presence of oxidized Mn species. ${ }^{[12,14]}$ The non-symmetric $M n 2 p_{3 / 2}$ peak indicates an overlapping of $\mathrm{Mn}^{2+}$ and $\mathrm{Mn}^{3+}$ contributions. The binding energy at $529.18 \mathrm{eV}$ in the $\mathrm{O} 1 \mathrm{~s}$ spectrum further confirms the existence of transition metal oxides (Figure $4 \mathrm{~d}$ ).
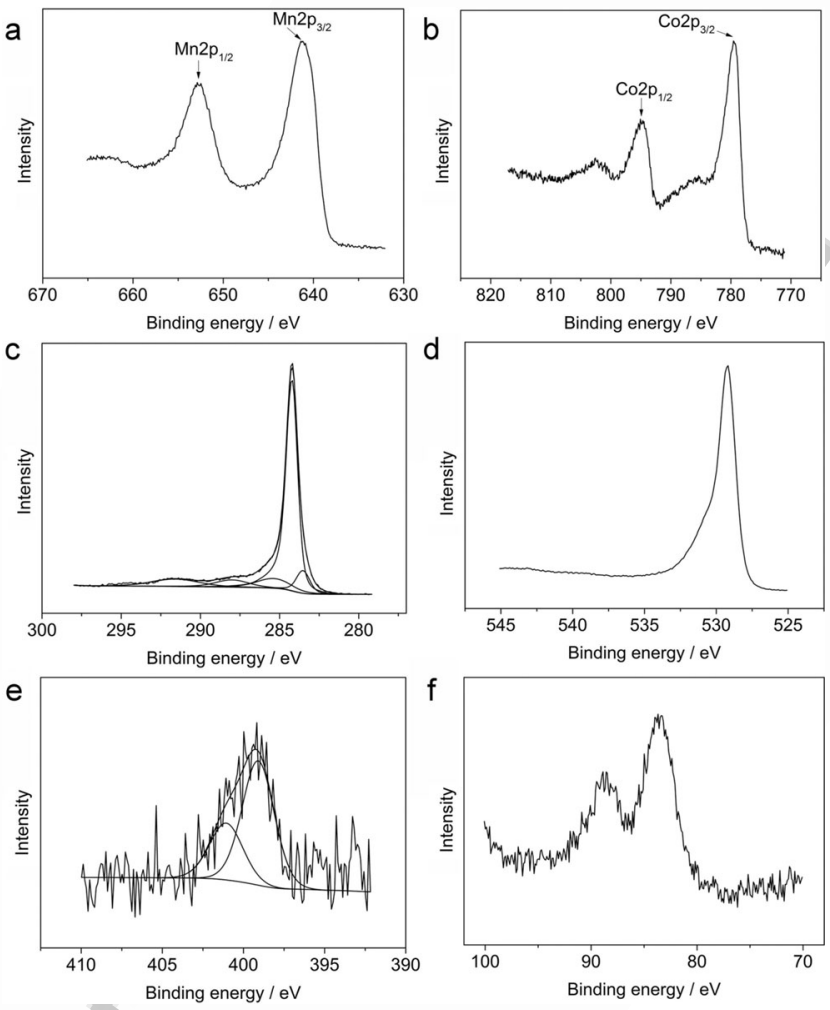

Figure 4. XPS analysis of the as prepared carbon- $\mathrm{Mn}_{x} \mathrm{Co}_{y} \mathrm{O}_{z}$ composite. Highresolution XPS spectra of Mn $2 \mathrm{p}(\mathrm{a}), \mathrm{Co} 2 \mathrm{p}$ (b), C 1s (c), O 1s (d), N 1s (e), and $\mathrm{Mn} 3 \mathrm{~s}$ (f).

XRD revealed the existence of three crystalline phases with different compositions (Figure 5). The reflection at $25.8^{\circ}$ is assigned to both graphitic and amorphous carbon. The second dominant reflection for graphitic carbon at $44^{\circ}$ cannot be observed because it is hidden underneath other signals. Therefore, a clear assignment of the carbon nature is not possible

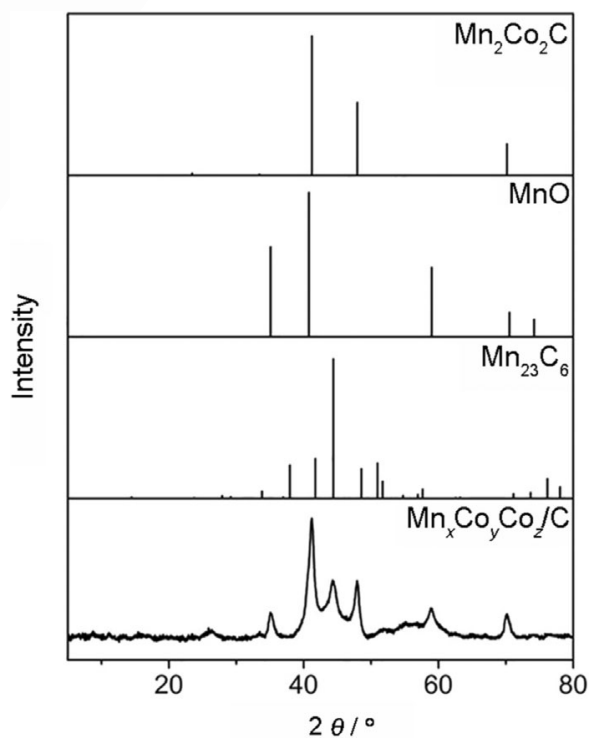

Figure 5. XRD patterns of carbon- $\mathrm{Mn}_{x} \mathrm{Co}_{y} \mathrm{O}_{z}$ and reference patterns of $\mathrm{Mn}_{2} \mathrm{CO}_{2} \mathrm{C}, \mathrm{MnO}$, and $\mathrm{Mn}_{23} \mathrm{C}_{6}$. 
based just on the XRD data. The reflections at $35.12^{\circ}$ and $58.85^{\circ}$ originate from the (111) and (220) planes, respectively, of cubic MnO (JCPDS 75-0625) with the space group Fm3m, whereas the most intense reflection at $41.20^{\circ}$ and the additional two at $47.93^{\circ}$ and $70.16^{\circ}$ correspond to the (111), (002) (200), and (220) (202) planes of tetragonal $\mathrm{Mn}_{2} \mathrm{CO}_{2} \mathrm{C}$ (JCPDS 893688) with the space group $P 4 / \mathrm{mmm}$. The remaining intense reflection at $44.28^{\circ}$ was assigned to the (511) plane of the cubic $\mathrm{Mn}_{23} \mathrm{C}_{6}$ phase (JCPDS 80-1701) with the space group Fm3m. The cubic crystal system of two of the phases is reflected in the highly cubic particle shape. The formation of carbides is in good agreement with previous reports on the heat treatment of PBA up to $600{ }^{\circ} \mathrm{C}$ in an inert gas atmosphere. ${ }^{[8]}$ The presence of $\mathrm{MnO}$ confirms the results of the TGA data regarding the observed weight increase during the cooling step. Although the XRD pattern was difficult to analyze and does therefore not preponderate, it confirms the clear results obtained by TEM and XPS, despite the $\mathrm{CoMn}_{2} \mathrm{O}_{4}$ spinel structure as seen in TEM not being observed in XRD, likely due to its very small size $(\sim 10 \mathrm{~nm})$.

\section{Electrochemical characterization}

A PBA/pBO ratio of 1:1 revealed the highest activity. Therefore, this ratio was chosen for a detailed study of the electrochemical performance of MnCo nanocubes embedded in a pBO derived $\mathrm{N}$-doped carbon matrix with respect to activity and stability towards OER. Carbon- $\mathrm{Mn}_{x} \mathrm{Co}_{y} \mathrm{O}_{z}$ showed high OER activity affording a current density of $1 \mathrm{mAcm}^{-2}$ at $1.54 \mathrm{~V}$ versus $\mathrm{RHE}$, and a current density of $10 \mathrm{~mA} \mathrm{~cm}^{-2}$ at $1.60 \mathrm{~V}$ versus RHE (Fig- ure $6 \mathrm{a}$ ), whereas the pure pyrolyzed pBO does not exhibit significant OER activity. The overpotential of $0.37 \mathrm{~V}$ required to reach a current density of $10 \mathrm{mAcm}^{-2}$ is significantly lower than other $\mathrm{Co}_{x} \mathrm{Mn}_{y} \mathrm{O}_{z}$-based catalysts, which have overpotentials in the range of $0.39-0.63 \mathrm{~V}^{[15]}$ The Tafel slope of carbon$\mathrm{Mn}_{x} \mathrm{Co}_{y} \mathrm{O}_{z}$ was $59 \mathrm{mV} \mathrm{dec}^{-1}$ (Figure $3 \mathrm{~b}$ ), which indicates very fast kinetics and a $\square$ charge $\square$ transfer coefficient $(\alpha)$ very close to $1(\alpha=2.303 R T / n F, \square$ please check equation, I changed $\alpha$ to $n$ and added definitions $\square$ with $R$ the universal gas constant, $T$ the temperature, $n$ the number of electrons transferred, and $F$ the Faraday constant). According to the Tafel slope, the discharge of $\mathrm{OH}^{-}$is the rate determining step. ${ }^{[16]}$ In situ Raman spectroscopy (Figure S16) indicates that the transition metal oxides are mainly responsible for catalyzing the OER whereas the $\mathrm{N}$-doped carbon matrix facilitates electrical interparticle connection. A recently developed stability assessment methodology ${ }^{[17]}$ was applied to evaluate the carbon$\mathrm{Mn}_{x} \mathrm{Co}_{y} \mathrm{O}_{z}$ catalyst and showed a negligible change in activity at current densities of 1.4 and $10 \mathrm{mAcm}^{-2}$ (Figure $6 \mathrm{c}$ ). Additional stability measurements were conducted using carbon$\mathrm{Mn}_{x} \mathrm{Co}_{y} \mathrm{O}_{z}$-modified $\mathrm{Ni}$ foam in a custom-built flow-through cell. ${ }^{[17]}$ During the accelerated galvanostatic stability test with an applied current density of $10 \mathrm{mAcm}^{-2}$ (with respect to the exposed surface of $\varnothing=8 \mathrm{~mm}$ ), the corresponding potential increased from an initial value of 1.61 to $1.68 \mathrm{~V}$ versus RHE after $67 \mathrm{~h}$ (Figure $6 \mathrm{~d}$ ). After the first $19 \mathrm{~h}$, the potential remained constant without any visible change until the end of the measurement indicating a stable state of the catalyst layer. Taking into account that $\mathrm{Ni}$ foam is by itself active for catalyzing the OER, analogous measurements were performed with pure $\mathrm{Ni}$

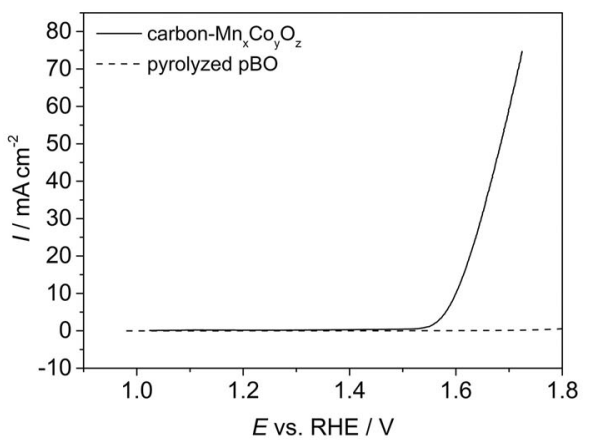

C

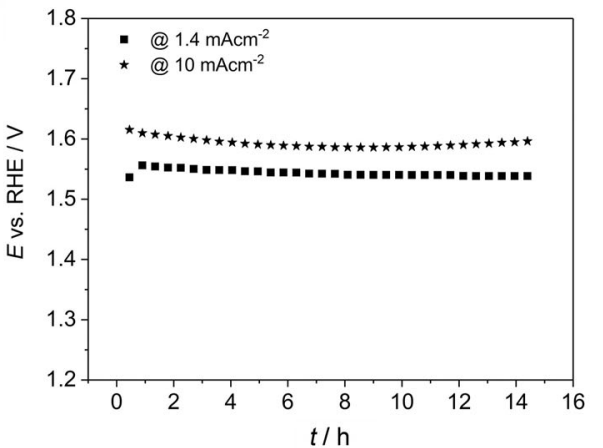

b

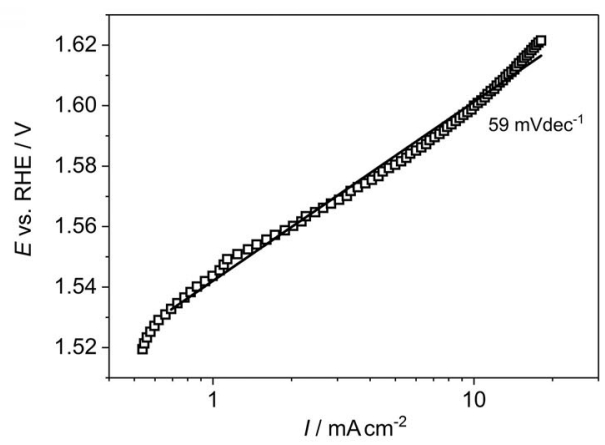

d

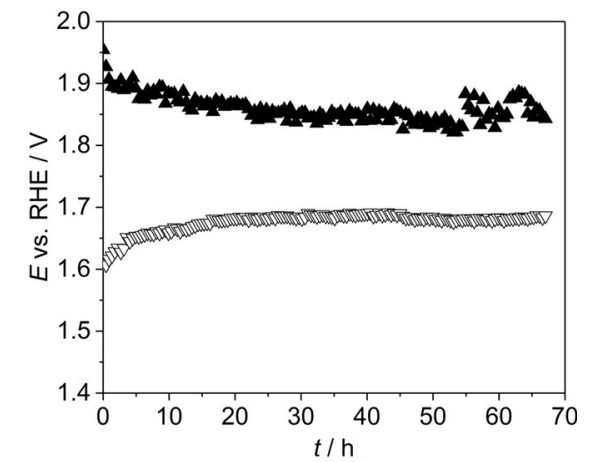

Figure 6. a) LSV $\left(5 \mathrm{mV} \mathrm{s}^{-1}, 0.1 \mathrm{M} \mathrm{KOH}, \mathrm{O}_{2}\right.$-saturated, $\left.1600 \mathrm{rpm}\right)$ of an activated carbon- $\mathrm{Mn}_{x} \mathrm{Co}_{y} \mathrm{O}_{z}$ electrode prepared with a pBO/PBA ratio of 1:1 in comparison with pure pyrolyzed pBO. b) Tafel plot derived from the LSV in (a). c) $E$ vs. $t$ curves at current densities of 1.4 and $10 \mathrm{mAcm}^{-2}$, respectively, extracted from stability measurement cycles. d) $E$ vs. $t$ curves of carbon- $\mathrm{Mn}_{x} \mathrm{Co}_{y} \mathrm{O}_{z}$ on $\mathrm{Ni}$ foam (white), and pure Ni foam (black) recorded in $0.1 \mathrm{M} \mathrm{KOH}, \mathrm{O}_{2}$-saturated at a current density of $10 \mathrm{~mA} \mathrm{~cm}^{-2}$ extracted from the stability measurement cycles. 
foam as control. The activity of pure $\mathrm{Ni}$ foam increased at the beginning of the measurement owing to the formation of $\mathrm{NiO}_{x} / \mathrm{NiOOH}$, however, it later remained constant at an overpotential of about $0.17 \mathrm{~V}$ higher than the carbon- $\mathrm{Mn}_{x} \mathrm{Co}_{y} \mathrm{O}_{z}$-modified $\mathrm{Ni}$ foam electrode (Figure $6 \mathrm{~d}$ ). The observed activity and stability can hence safely be attributed to the properties of the suggested carbon- $\mathrm{Mn}_{x} \mathrm{Co}_{y} \mathrm{O}_{z}$ catalyst.

\section{Conclusions}

We suggest a novel approach for the preparation of highly active and stable catalyst-modified electrodes for the oxygen evolution reaction (OER). Benzoxazine (BO) monomers were deposited together with the prussian blue analogue (PBA) $\mathrm{K}_{m} \mathrm{Mn}_{x}\left[\mathrm{Co}(\mathrm{CN})_{6}\right]_{y} \times n \mathrm{H}_{2} \mathrm{O}$ on an electrode surface followed by temperature-induced polymerization, leading to the formation of a homogeneous polymer/PBA composite film owing to the near-zero shrinkage property of polybenzoxazine (pBO). Subsequent pyrolysis formed an $\mathrm{N}$-doped carbon matrix embedding catalytically active $\mathrm{Mn}_{x} \mathrm{Co}_{y} \mathrm{O}_{z}$ nanocubes. The $\mathrm{pBO}$ content showed a significant impact on the catalytic activity. Owing to the intrinsic stability of the $\mathrm{pBO}$, only $5 \%$ loss in activity during accelerated galvanostatic stability tests at $10 \mathrm{mAcm}^{-2}$ on carbon- $\mathrm{Mn}_{x} \mathrm{Co}_{y} \mathrm{O}_{z}$ sprayed on Ni foam after $67 \mathrm{~h}$ was observed.

\section{Experimental Section}

\section{Electrode preparation}

Carbon- $\mathrm{Mn}_{x} \mathrm{Co}_{y} \mathrm{O}_{z}$ modified glassy carbon electrodes were prepared according to the following procedure: a glassy carbon rod ( $\varnothing=3 \mathrm{~mm}, \mathrm{~L} \approx 1 \mathrm{~cm}$; HTW, Germany) was polished successively with polishing pastes of decreasing particle sizes ( $3 \mu \mathrm{m}$ diamond paste, $1 \mu \mathrm{m}$ and $0.3 \mu \mathrm{m} \mathrm{Al}_{2} \mathrm{O}_{3}$ paste; Leco, USA) to obtain a mirrorlike surface. The polished electrodes were immersed in a 1:1 mixture of ethanol and ultra-pure water and sonicated for $15 \mathrm{~min}$. The dried electrodes were drop-coated with an ink $(7.2 \mu \mathrm{L})$ containing $\mathrm{K}_{m} \mathrm{Mn}_{x}\left[\mathrm{Co}(\mathrm{CN})_{6}\right]_{y} \times n \mathrm{H}_{2} \mathrm{O}\left(5 \mathrm{mg} \mathrm{mL}^{-1}\right)$ and Araldite $35600 \mathrm{CH}$ (Huntsman, USA) $\left(0,0.1,0.5,1,2\right.$, or $5 \mathrm{mg} \mathrm{mL}^{-1}$ ) in acetonitrile (J. T. Baker, Netherlands), leading to an initial loading of $0.5 \mathrm{mg} \mathrm{cm}^{-2}$. The catalyst inks were sonicated for $20 \mathrm{~min}$ prior to drop-coating. The drop-coated electrodes were placed into a three-zone tube furnace and a multistep heating program was applied $\left(160^{\circ} \mathrm{C} / 2 \mathrm{~h} ; 180^{\circ} \mathrm{C}\right.$ / $\left.2 \mathrm{~h} ; 200^{\circ} \mathrm{C} / 2 \mathrm{~h} ; 220^{\circ} \mathrm{C} / 1 \mathrm{~h} ; 240^{\circ} \mathrm{C} / 1 \mathrm{~h} ; 600^{\circ} \mathrm{C} / 2 \mathrm{~h}\right)$ under Ar atmosphere. Electrodes prepared with a pBO/PBA ratio of $1: 1$ and $5 \mathrm{mg} \mathrm{mL}^{-1}$ PBA had an estimated final loading of $0.15 \mathrm{mg} \mathrm{cm}^{-2} \mathrm{cal}-$ culated from the weight loss of $70 \%$ as shown in TGA. Ni foam electrodes ( $1.6 \mathrm{~mm}$ thickness, $A_{\text {geometric. }}=0.64 \mathrm{~cm}^{2}$; Goodfellow, Germany) were spray-coated with a PBA/Araldite ink (ratio 1:1) and heat-treated as described above. The resulting electrodes had a catalyst loading of $0.625 \mathrm{mg} \mathrm{cm}^{-2}$.

\section{Electrochemical measurements}

All electrochemical measurements were performed in a one compartment three-electrode configuration with the modified glassy carbon electrode $\left(\mathrm{GCE}, \varnothing=3 \mathrm{~mm} ; A_{\text {geometric }}=0.071 \mathrm{~cm}^{2}\right)$ as working electrode (WE), a platinum mesh as counter electrode (CE), and a $\mathrm{Ag} / \mathrm{AgCl} / 3 \mathrm{M} \mathrm{KCl}$ as reference electrode (RE) using an Autolab potentiostat/galvanostat (Metrohm Autolab, Netherlands) at room temperature. Modified glassy carbon rods were fixed onto a stainless-steel holder for rotating disk electrode (RDE) measurements. The glassy carbon rods were insulated by wrapping a PTFE sealing tape very tightly around the rod so that only the disk-shaped catalyst-modified electrode was exposed to the electrolyte. The OER activity of the catalysts was investigated using RDE voltammetry in oxygen-saturated $\mathrm{KOH}(0.1 \mathrm{M})$ at room temperature at a scan rate of $5 \mathrm{mV} \mathrm{s}^{-1}$ to reduce capacitive current contributions. Catalyst activation was done by cycling the potential 50 times between 0.0 and $1.0 \mathrm{~V}$ vs. $\mathrm{Ag} / \mathrm{AgCl} / 3 \mathrm{M} \mathrm{KCl}$ at a scan rate of $50 \mathrm{mVs}^{-1}$. The longterm measurement procedure consisted of cycles of electrochemical impedance spectroscopy (EIS), cyclic voltammetry (0.0-1.0 V vs. $\mathrm{Ag} / \mathrm{AgCl} 3 \mathrm{M} \mathrm{KCl}, 5 \mathrm{mVs}^{-1}$ ) and galvanostatic chronopotentiometry (900 s). ${ }^{[17]}$ The measurements were done either with a RDE (GCE, $1600 \mathrm{rpm}$ ) or an electrochemical flow-through cell (Ni foam electrodes) in oxygen-saturated $\mathrm{KOH}\left(0.1 \mathrm{M}\right.$, flow rate: $\left.30 \mathrm{~mL} \mathrm{~min}^{-1}\right) .^{[17]}$ In situ Raman spectra were recorded during chronoamperometric measurements at different potentials in $\mathrm{KOH}(0.1 \mathrm{M})$. All potentials are referred to the reversible hydrogen electrode (RHE) and converted according to: $E_{\mathrm{RHE}}=E_{\mathrm{appl}}+E_{\mathrm{Ag} / \mathrm{AgCl}}^{0}+0.059 \mathrm{pH}$. The $\mathrm{pH}$ value was calculated using: $\mathrm{pH}=14+\log \mathrm{OH}^{-}+\log \gamma$

where the $\mathrm{OH}^{-}$concentration was corrected using the $\mathrm{KOH}$ purity $(85 \%)$ and the activity coefficient of a $0.1 \mathrm{M} \mathrm{KOH} \gamma=0.766$ (mean of the activity coefficients from Ref. [18]). By this, the $\mathrm{pH}$ value for the used $0.1 \mathrm{M} \mathrm{KOH}$ solution was determined to be 12.81 . The potential was further corrected for the uncompensated ionic resistance of the electrolyte according to $E_{\mathrm{RHE}}^{\mathrm{corr}}=E_{\mathrm{RHE}}-i R$. The uncompensated resistance was determined by means of EIS using an AC perturbation of $10 \mathrm{mV}$ ( $\mathrm{rms}$ ) at the open-circuit potential of the respective electrode in the frequency range from $100 \mathrm{kHz}$ to $10 \mathrm{~Hz}$.

\section{Physical characterization}

XRD measurements were performed using a PANalytical thetatheta powder diffractometer equipped with a CuK $\alpha$ radiation source. Scans were run from 5 to $80^{\circ}$ with a step width of $0.01^{\circ}$. Raman spectra were recorded using a Jobin-Yvon iHR550 spectrometer (Germany) equipped with a TE cooled charge coupled device. Excitation was done with a laser MPC 6000, Model Ignis 660 (Laser Quantum, UK) at a wavelength of $661 \mathrm{~nm}$ (in situ) or $532 \mathrm{~nm}$ ( $D$ and $G$ band). The typical laser power was $11 \mathrm{~mW}$ and the spectra were acquired for $10 \mathrm{~s}$. To focus the laser in solution, an immersible objective (Olympus, Japan) with a 60 times magnification was employed. SEM images and EDX were performed using a Quanta 3D FEG SEM (FEl, USA) operated at $20.0 \mathrm{kV}$ for SEM imaging and at $30 \mathrm{kV}$ for EDX analysis and mapping. XPS spectra were recorded on a K-Alpha instrument (Thermo Scientific, USA) equipped with a monochromatic $\mathrm{AlK}_{\alpha}$ source $(1486.6 \mathrm{eV})$. The measurements were performed at a base pressure of $2 \times 10^{-9} \mathrm{mbar}$ with pass energies of 200 and $20 \mathrm{eV}$ for survey and high-resolution spectra, respectively. Deconvolution of the $C 1 \mathrm{~s}$ and $N 1 \mathrm{~s}$ peaks was performed after subtraction of Smart background. TGA curves were recorded on a Q500 (TA Instruments, USA). A combination of non-isothermal and isothermal steps were run under a nitrogen atmosphere, following a similar heating program like the one used for the electrode preparation: $10^{\circ} \mathrm{C} \mathrm{min}^{-1}$ ramp from 20 to $160^{\circ} \mathrm{C}$, isothermal for $2 \mathrm{~h}$ at $160^{\circ} \mathrm{C}, 10^{\circ} \mathrm{C} \mathrm{min}^{-1}$ ramp from 160 to $180^{\circ} \mathrm{C}$, isothermal for $2 \mathrm{~h}$ at $180^{\circ} \mathrm{C}, 10^{\circ} \mathrm{C} \mathrm{min}^{-1}$ ramp from 180 to $200^{\circ} \mathrm{C}$, isothermal for $2 \mathrm{~h}$ at $200^{\circ} \mathrm{C}, 10^{\circ} \mathrm{C} \mathrm{min}^{-1}$ ramp from 200 to $220^{\circ} \mathrm{C}$, isothermal for $1 \mathrm{~h}$ at $220^{\circ} \mathrm{C}, 10^{\circ} \mathrm{C} \mathrm{min}^{-1}$ ramp from 220 to $240{ }^{\circ} \mathrm{C}$, isothermal for $1 \mathrm{~h}$ at $240{ }^{\circ} \mathrm{C}, 10^{\circ} \mathrm{C} \mathrm{min}^{-1}$ ramp from 240 to $600^{\circ} \mathrm{C}$, isothermal for $2 \mathrm{~h}$ at $600^{\circ} \mathrm{C}$, cooling at $1^{\circ} \mathrm{Cmin}^{-1}$ from 600 to $190^{\circ} \mathrm{C}$. TEM studies were conducted using a field-emission gun FEI 
Tecnai F20 microscope operated at $200 \mathrm{kV}$, which was equipped with an HAADF detector and Quantum Gatan Image Filter (GIF) for EELS analyses.

\section{Manganese hexacyanocobaltate synthesis}

$\mathrm{K}_{m} \mathrm{Mn}_{x}\left[\mathrm{Co}(\mathrm{CN})_{6}\right]_{y} \times n \mathrm{H}_{2} \mathrm{O}$ was synthesized using a co-precipitation reaction adapted from Ref. [19]. $\mathrm{Mn}\left(\mathrm{CH}_{3} \mathrm{COO}\right)_{2 \times} 4 \mathrm{H}_{2} \mathrm{O}(1.219 \mathrm{mmol}$, Sigma-Aldrich, Germany) and PVP $\mathbf{\square}$ please define $\mathbf{0}(2.445 \mathrm{~g})$ (K-30) were dissolved in a mixture of ethanol (techn.) and ultrapure water $(325 \mathrm{~mL}, \quad 3: 1) \quad$ (solution $\left.\mathrm{A}, \quad 3.75 \mathrm{mM} \mathrm{Mn}^{2+}\right) . \mathrm{K}_{3}\left[\mathrm{Co}(\mathrm{CN})_{6}\right]$ (0.652 mmol, Sigma-Aldrich, Germany) was dissolved in ultrapure water $(163 \mathrm{~mL})\left(4 \mathrm{~mm} \mathrm{Co}{ }^{3+}\right.$, solution B). Solution B was added into the stirred solution $A$ using a peristaltic pump with a volume flow of $1.5 \mathrm{~mL} \mathrm{~min}{ }^{-1}$. Precipitation started immediately. The reaction mixture was stirred for $1 \mathrm{~h}$ at room temperature and then allowed to stand for $24 \mathrm{~h}$. The precipitate was collected by centrifuging the reaction mixture in $50 \mathrm{~mL}$ Falcon tubes $(4000 \mathrm{rpm}, 50 \mathrm{~min}$ ) and washed 2 times with absolute ethanol (each $10 \mathrm{~mL}$ ). The solid was dried overnight at $60^{\circ} \mathrm{C}$ yielding $284 \mathrm{mg}$ of the product.

\section{Acknowledgements}

The authors are grateful to the Deutsche Forschungsgemeinschaft (DFG) in the framework of the Cluster of Excellence "Resolv" (EXC1069) and the Bundesministerium für Bildung und Forschung (BMBF) in the frameworks of the project "Mangan" (FKZ 03EK3548). J.A. and A.G. acknowledge the funding from the Generalitat de Catalunya 2014SGR1638.

\section{Conflict of interest}

The authors declare no conflict of interest.

Keywords: catalyst stability - electrocatalysis - oxygen evolution reaction $\cdot$ polybenzoxazine $\cdot$ prussian blue analogue

[1] P. Du, R. Eisenberg, Energy Environ. Sci. 2012, 5, 6012-6021.

[2] a) J. Masa, P. Weide, D. Peeters, I. Sinev, W. Xia, Z. Sun, C. Somsen, M. Muhler, W. Schuhmann, Adv. Energy Mater. 2016, 6, 15023131; b) Y. Liang, X. Sun, A. M. Asiri, Y. He, Nanotechnology 2016, 27, 12LT01; c) J.
Masa, S. Barwe, C. Andronescu, I. Sinev, A. Ruff, K. Jayaramulu, K. Elumeeva, B. Konkena, B. Roldan Cuenya, W. Schuhmann, ACS Energy Lett. 2016, 1, 1192-1198; d) M. S. Burke, L. J. Enman, A. S. Batchellor, S. Zou, S. W. Boettcher, Chem. Mater. 2015, 27, 7549-7558.

[3] a) L. Wang, Y. Wu, R. Cao, L. Ren, M. Chen, X. Feng, J. Zhou, B. Wang ACS Appl. Mater. Interfaces 2016, 8, 16736-16743; b) X. Lu, C. Zhao Nat. Commun. 2015, 6, 6616.

[4] a) M. Gong, Y. Li, H. Wang, Y. Liang, J. Z. Wu, J. Zhou, J. Wang, T. Regier, F. Wei, H. Dai, J. Am. Chem. Soc. 2013, 135, 8452-8455; b) J. Geng, L. Kuai, E. Kan, Q. Wang, B. Geng, ChemSusChem 2015, 8, 659-664.

[5] H. Ishida, T. Agag, Handbook of Benzoxazine Resins, Elsevier, Amsterdam, 2011

[6] a) H. Yee Low, H. Ishida, Polymer 1999, 40, 4365-4376; b) C. H. Lin, S. X. Cai, T. S. Leu, T. Y. Hwang, H. H. Lee, J. Polym. Sci. Part A 2006, 44, $3454-$ 3468.

[7] K. Hemvichian, H. Ishida, Polymer 2002, 43, 4391-4402.

[8] C. Aparicio, L. Machala, Z. Marusak, J. Therm. Anal. Calorim. 2012, 110, $661-669$.

[9] A. V. Shchukarev, D. V. Korolkov, Cent. Eur. J. Chem. 2004, 2, 347-362.

[10] a) S. T. Oyama, The chemistry of transition metal carbides and nitrides, Blackie Academic, London, 1996; b) J. D. Oxley, M. M. Mdleleni, K. S. Suslick, Catal. Today 2004, 88, 139-151; c) A. Wiltner, C. Linsmeier, T. Jacob, J. Chem. Phys. 2008, 129, 084704.

[11] H. Zhang, W. Gu, R. Zhu, Q. Ran, Y. Gu, High Temp. Mater. Proc. 2015, 34,

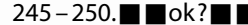

[12] M. C. Biesinger, B. P. Payne, A. P. Grosvenor, L. W. Lau, A. R. Gerson, R. S. Smart, Appl. Surf. Sci. 2011, 257, 2717-2730.

[13] P. Konova, M. Stoyanova, A. Naydenov, S. Christoskova, D. Mehandjiev, Appl. Catal. A 2006, 298, 109-114.

[14] B. Fleury, V. Huc, L. Catala, P. Jegou, L. Baraton, C. David, S. Palacin, T. Mallah, CrystEngComm 2009, 11, 2192-2197.

[15] a) Z. Liu, C. Yu, X. Han, J. Yang, C. Zhao, H. Huang, J. Qiu, ChemElectroChem 2016, 3, 906-912; b) P. W. Menezes, A. Indra, N. R. Sahraie, A Bergmann, P. Strasser, M. Driess, ChemSusChem 2015, 8, 164-171; c) A Zhao, J. Masa, W. Xia, A. Maljusch, M.-G. Willinger, G. Clavel, K. Xie, R. Schlogl, W. Schuhmann, M. Muhler, J. Am. Chem. Soc. 2014, 136, $7551-$ 7554; d) D. Li, H. Baydoun, C. N. Verani, S. L. Brock, J. Am. Chem. Soc. 2016, 138, 4006-4009; e) D. Wang, X. Chen, D. G. Evans, W. Yang, Nanoscale 2013, 5, 5312-5315.

[16] J. O. Bockris, J. Chem. Phys. 1956, 24, 817-827.

[17] A. Maljusch, O. Conradi, S. Hoch, M. Blug, W. Schuhmann, Anal. Chem. 2016, 88, 7597-7602.

[18] a) L. A. Bromley, AIChE J. 1973, 19, 313-320; b) M. Knobel, J. Am. Chem. Soc. $1923,45,70-76$.

[19] L. Hu, P. Zhang, H. Zhong, X. Zheng, N. Yan, Q. Chen, Chem. Eur. J. 2012, 18, 15049-15056

Manuscript received: April 7, 2017

Final Article published: $\mathbf{\square} \mathbf{\square}, 0000$ 


\section{FULL PAPERS}

S. Barwe, C. Andronescu, J. Masa,

E. Ventosa, S. Klink, A. Genç, J. Arbiol,

W. Schuhmann*

a

Polybenzoxazine-Derived N-doped Carbon as Matrix for Powder-Based Electrocatalysts
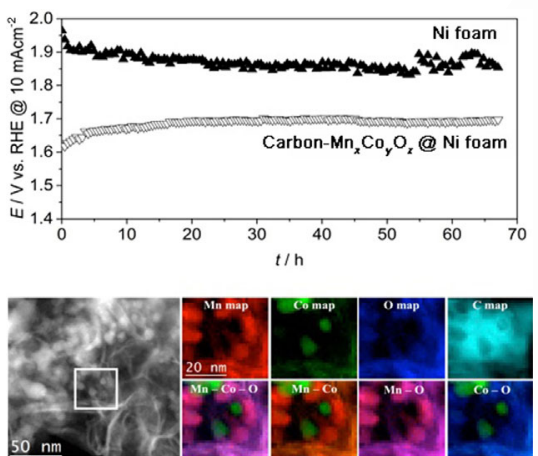

Matrix reloaded: Powder oxygen evolution reaction (OER) catalysts are commonly immobilized on electrodes by means of embedding in a Nafion matrix, even in alkaline environment. We present an alternative approach using the unique properties of benzoxazine polymers. Polymerization and pyrolysis of a benzoxazine/prussian blue analogue powder composite leads to highly stable immobilized OER active electrocatalyst particles on the electrode surface.

A new matrix for powder-based \#electrocatalysts based on \#polybenzoxazine @ruhrunibochum @icn2nano

@icreacommunity SPACE RESERVED FOR IMAGE AND LINK

Share your work on social media! ChemSusChem has added Twitter as a means to promote your article. Twitter is an online microblogging service that enables its users to send and read text-based messages of up to 140 characters, known as "tweets". Please check the pre-written tweet in the galley proofs for accuracy. Should you or your institute have a Twitter account, please let us know the appropriate username (i.e., @accountname), and we will do our best to include this information in the tweet. This tweet will be posted to the journal's Twitter account @ChemSusChem (follow us!) upon online publication of your article, and we recommended you to repost ("retweet") it to alert other researchers about your publication.

Please check that the ORCID identifiers listed below are correct. We encourage all authors to provide an ORCID identifier for each coauthor. ORCID is a registry that provides researchers with a unique digital identifier. Some funding agencies recommend or even require the inclusion of ORCID IDs in all published articles, and authors should consult their funding agency guidelines for details. Registration is easy and free; for further information, see http://orcid.org/.

Stefan Barwe

Dr. Corina Andronescu

Dr. Justus Masa

Dr. Edgar Ventosa

Dr. Stefan Klink

Dr. Aziz Genç

Prof. Dr. Jordi Arbiol

Prof. Dr. Wolfgang Schuhmann http://orcid.org/0000-0003-2916-5223 